\section{THE SPREAD OF TUMOURS IN THE HUMAN BODY}

By R. A. Willis, M.D., D.Sc., F.R.C.P. Pp. ix +475 , with 85 illustrations. London: Butterworth \& Co., 1952. 63s.

Along with 'Pathology of Tumours' this book is almost certain to remain the standard reference text for students of oncology for a long time, since Ewing's book is now out of print. It is arranged in two main parts and the first 14 chapters give a very sound and reasoned discussion of the many and varied ways in which tumours may spread and produce their metastases. The only statement which this reviewer cannot accept is on p. II3, that ' even in extreme leucocytosis no mitoses are to be found in the blood leucocytes.' Mitotic figures are, in fact, found in the blood stream occasionally in severe cases of glandular fever and in leukaemia or allied conditions even when there is no leucocytosis. The second part consists of 15 chapters describing the secondary tumours of the various organs. It is perhaps a little surprising that when dealing with diffuse infiltration without focal tumour formation in the spleen (p. 207) the importance of extramedullary haemopoiesis or myeloid metaplasia in the pulp is not stressed. This is almost invariably present when the spleen is diffusely infiltrated. That no sharp distinction can be made between osteoplastic and osteoclastic metastases in bones (p. 24I) is a statement which is endorsed by anyone who has seen sections of bone and it should be more widely appreciated by clinicians. In the discussion of leuco-erythroblastic reactions, a useful name which is, however, not mentioned as such (p. 248), the terms haemoglobin percentage, hyperchromia and relative lymphocytosis are unfortunately used, and the colour index is given undue importance. They are not in accord with modern practice and it is doubtful if hyperchromia is really possible. In many cases of carcinomatosis of the skeleton the blood platelets are increased, sometimes to as much as a million per c.mm., but the paragraph dealing with this feature only mentions three such cases accompanied by thrombocytopenia which usually only develops after prolonged or intense courses of radiotherapy.

In an appendix the author's necropsy technique is described and a synopsis of his series of 500 consecutive necropsies on cases of malignant disease is made. This is followed by more than 80 pages of references to papers on tumours which are given their full titles. It reflects really catholic reading and an immense amount of work. It is a pity that all the illustrations are put together at the end of the book. This seems to be the only concession to economy made in this book. The photomicrograph of invasion of the peri-anal skin in carcinoma of the rectum (Figs. 80 and $8 \mathrm{r}$ ) deserves particular mention.

Pathologists and particularly morbid anatomists will have to use this book and refer to it frequently.

While many may find it perhaps a little awkward to look up particular points and might have wel- comed more cross-references and a better index they will all be grateful to Professor Willis for the opportunity of benefiting from his wide experiencer and for his full and balanced review of the subject $\frac{Q}{c}$

E.N.

\section{DISEASES OF THE NERVOUS SYSTEM}

By F. M. R. WALShe, M.D., D.Sc., F.R.S. 7 th Edition. Pp. xvi +365 , with 63 illustrations Edinburgh: E. \& S. Livingstone Ltd. I $952 \%$ 24s.

This popular textbook needs no introduction Since the first edition in 1940 it has been increas- $\omega$ ly widely read and enjoyed, a French anto Spanish edition being called for in 1948. For its size and scope one may say with confidence that, in neurology, it is the best in the English language 0 What it sets out to do, to present a selection ofw neurology for the student and practitioner, it doeș well nigh perfectly in a simple yet elegant fashion.Throughout one is aware of the author's charactero and way of thinking, gleaming through the nicelyo' separated stakes forming the palisade of facts, a palisade that, in so many textbooks, seems toobscure the man presenting them. In this book there is no pontifical humbugging; reasonablenesso pervades it and the reader is told what is not cer- $\frac{\hat{\rho}}{5}$ tainly known as well as what the author feels is wellsubstantiated fact. It is a book of stimulatiog opinions, balanced argument, and not a dut laundry-list of probabilities and possibilities. Yeto the most junior student of clinical medicine need not shy from it as lacking meat to get his teeth into.

This seventh edition contains little new materialo but the quality of it inspires confidence that the $\frac{\mathscr{Q}}{\Phi}$ author has used his renowned critical judgment in striking a balance between what is and what is not $\overrightarrow{\overrightarrow{0}}$ important in fundamentals. The chapter on the 3 psychoneuroses, unlike many of its kind, should be understood by all. This thoroughly digestible and delightfully written book should be read by all final year students and, later yet again, by those going up 3 for a higher examination in medicine. Dr. Walshe's. limpid style might well be set as a model for 3 medical textbooks.

\section{AIDS TO OSTEOLOGY}

By Nils L. EckofF, M.S., F.R.C.S. 5th Edition.

Pp. viii +264 , with 42 illustrations. London: N Baillière, Tindall \& Cox, 1952. 6s. 6d.

In this book a large subject is dealt with concisely and accurately. There is an adequate descrip- $-\mathcal{N}$ tion of the major anatomical markings of all the bones followed in each case by a list of ligamentous and muscular attachments.

This should prove. a useful book to anatomy students and particularly so to those who are re-vising the subject for their final examinations. 